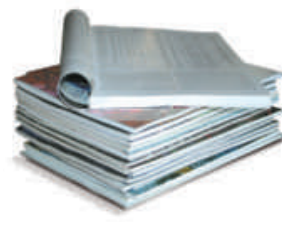

PUBLICATION BIAS

\title{
Ghosts still present in the medical machine
}

\section{VANCOUVER}

The medical literature continues to be haunted by ghostwriting - a practice that, in its most extreme form, involves pharmaceutical companies designing and paying for studies or reviews, then seeking a guest author to be credited while the company goes unacknowledged. The problem persists, said experts last week, despite recent drug-company policy changes and efforts by journals to cut down on the practice (see 'Spectre of industry bias').

A new survey attempting to quantify the phenomenon looked at more than 600 authors who had published papers in six major medical journals in 2008. Of them, $7.8 \%$ indicated there was a 'ghost' lurking behind the paper - someone who contributed significantly, perhaps as a writer or statistician, but who wasn't credited as an author or elsewhere. In a similar 1996 survey, the percentage that identified ghosts was $11 \%$. "It is still a problem," says Josef Wislar, a research analyst for the Journal of the American Medical Association (JAMA) in Chicago, Illinois, who presented the work in Vancouver, Canada, at the 10-12 September Sixth International Congress on Peer Review and Biomedical Publication.

Recent media reports have described how pharmaceutical giant Merck sponsored work about its painkiller Vioxx (rofecoxib), and Wyeth did the same for its hormone-replacement therapy Prempro, without being fully acknowledged in some resulting papers. And GlaxoSmithKline ran a programme in which employees approached doctors to help them write up their experiences with the depression

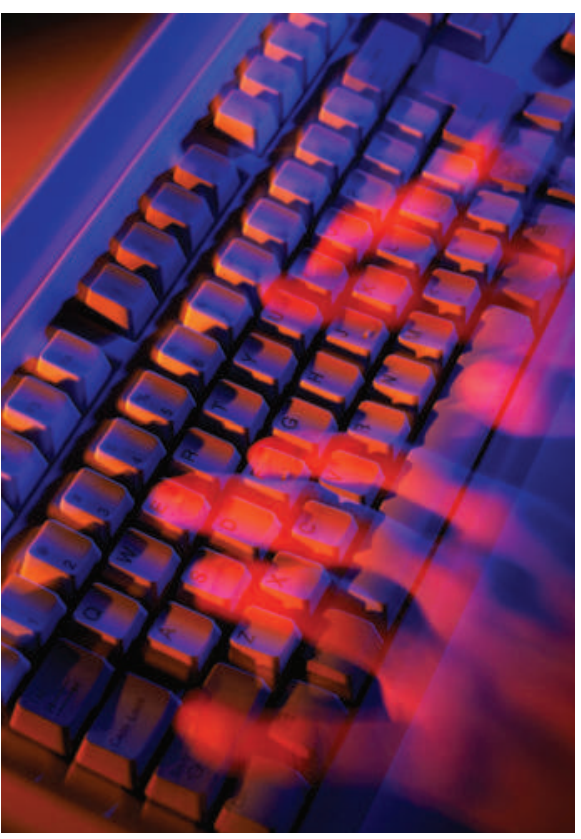

A paper's authors are not always apparent from the author list.

medicine Paxil (paroxetine). Three published case studies resulted, none acknowledging the assistant writer, says company spokesman Kevin Colgin.

These high-profile cases involve papers published largely in the late 1990s or early 2000s, and Merck, Wyeth and GlaxoSmithKline have all since changed their policies to strengthen rules on disclosure. Yet medical-journal editors say the issue continues.

"We receive several manuscripts a month that are suspicious," says William Tierney, co-editor-in-chief of the Journal of General

Internal Medicine in Indianapolis, Indiana. These include, for example, favourable reviews for new drugs apparently penned by authors who had not previously published on that topic.

Whether such ghostwriting has an adverse effect is hard to pin down. The aim of sponsoring and writing papers is simply to "broaden knowledge about the latest science”, says Wyeth spokesman Doug Petkus. But Drummond Rennie, deputy editor at JAMA, says that ghostwritten papers tend to have more positive conclusions and can be used to market off-label uses of drugs.

Journal editors can fight the practice by having strict rules on disclosure and by publishing the specific contributions of each author, says Jenny White, a research analyst at the University of California, San Francisco. In work presented at the Vancouver meeting, White found that among journals targeted by a ghostwriting campaign by Parke-Davis - a subsidiary of Pfizer - for Neurontin (gabapentin), used to relieve neuropathic pain, the journals that published the work were less likely to have strong rules about authorship and disclosure than those that did not. Still, only 4 of 26 journals she studied explicitly mention ghostwriting in their policies today.

The World Association for Medical Editors recommends that journal editors "publish a notice that a manuscript has been ghost written, along with the names of the responsible companies and the submitting author", alert the academic institution involved and provide the media with details if contacted about the case.

Many journal editors do this. "We name and shame constantly," says Rennie. But, says Christine Laine, editor of the Annals of Internal Medicine in Philadelphia, Pennsylvania, the only way to stop the ghostwriting is if "respected names in academia" stop being "willing to put their names on papers they have not been fully involved in, or without proper acknowledgements".

"I work regularly with scientists employed by drug companies, and to a person they are honest, ethical and interested in the truth," says Tierney. "These ghostwriting misadventures are the product of the drug companies' marketing offices, and they are maddening."

Nicola Jones 